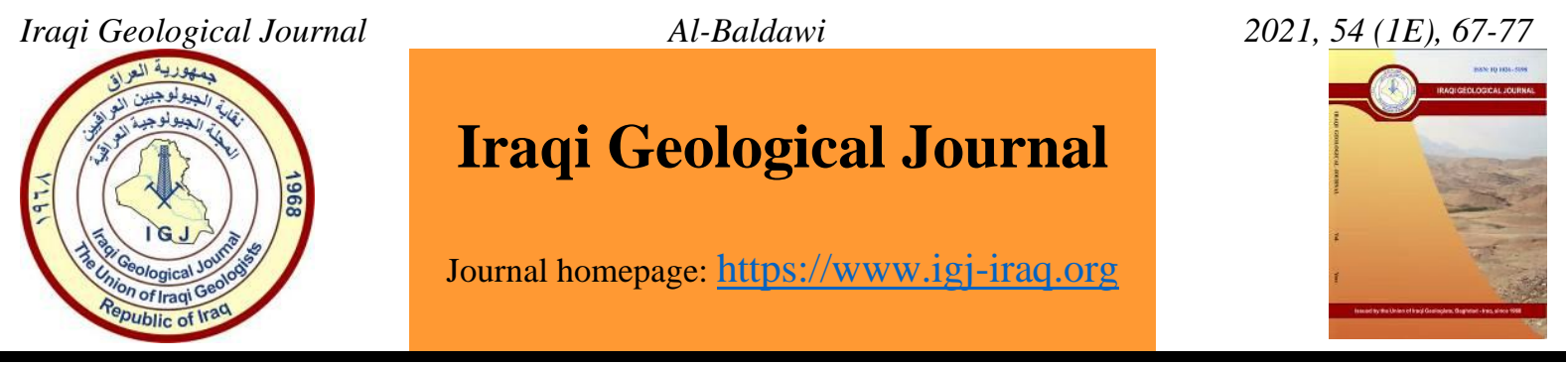

\title{
Evaluation of Petrophysical Properties Using Well Logs of Yamama Formation in Abu Amood Oil Field, Southern Iraq
}

\author{
Buraq Adnan Al-Baldawi ${ }^{1, *}$ \\ ${ }^{1}$ Department of Geology, College of Science, University of Baghdad \\ *Correspondence: buraq.hussein@sc.uobaghdad.edu.iq
}

Received: 20 February 2021; Accepted: 31 March 2021; Published: 31 May 2021

\begin{abstract}
The petrophysical analysis is very important to understand the factors controlling the reservoir quality and production wells. In the current study, the petrophysical evaluation was accomplished to hydrocarbon assessment based on well log data of four wells of Early Cretaceous carbonate reservoir Yamama Formation in Abu-Amood oil field in the southern part of Iraq. The available well logs such as sonic, density, neutron, gamma ray, SP, and resistivity logs for wells AAm-1, AAm-2, AAm-3, and AAm-5 were used to delineate the reservoir characteristics of the Yamama Formation. Lithologic and mineralogic studies were performed using porosity logs combination cross plots such as density vs. neutron cross plot and M-N mineralogy plot. These cross plots show that the Yamama Formation consists mainly of limestone and the essential mineral components are dominantly calcite with small amounts of dolomite. The petrophysical characteristics such as porosity, water and hydrocarbon saturation and bulk water volume were determined and interpreted using Techlog software to carried out and building the full computer processed interpretation for reservoir properties. Based on the petrophysical properties of studied wells, the Yamama Formation is divided into six units; (YB-1, YB-2, YB-3, YC-1, YC-2 and YC-3) separated by dense non porous units (Barrier beds). The units (YB-1, YB-2, YC-2 and YC-3) represent the most important reservoir units and oil-bearing zones because these reservoir units are characterized by good petrophysical properties due to high porosity and low to moderate water saturation. The other units are not reservoirs and not oil-bearing units due to low porosity and high-water saturation.
\end{abstract}

Keywords: Yamama Formation; Abu-Amood Oilfield; Techlog software, Formation

\section{Introduction}

Well log is an important tool available to petroleum geologists. Log analysis is used to describe the porosity, lithology, and geometry of the pores, in addition to permeability is often used to provide an estimated interpretation on reservoir levels of oil. (Asquith and Krygowski, 2004). The Yamama Formation is an important oil-producing formation, southern Iraq. The formation was deposited during the retrogressive depositional cycle (Berriasian - Aptian) south of Iraq. The cycle is divided into Zubair, Ratawi, Yamama, Shuiaba, and Sulaiy formations from shore to deep basin. (Buday, 1980). Abu Amood oil field is one of the important fields in Iraq. The first exploration well in the Abu Amood oil field (AAm-1) was drilled during 1980 for exploring the potential of hydrocarbons. In this study, the

DOI: 10.46717 /igj.54.1E.6Ms-2021-05-27 
petrophysical properties of the Yamama Formation in the Abu Amood oil field will be discussed using the data gathered from the available logs of four selected wells. This study focuses on interpreting petrophysical properties and formation evaluation for the Yamama reservoir. The pre-interpretation allows the analysis of effective porosity, water saturation, and all variables needed in the interpretation process using Techlog Software.

\section{Study Area}

Abu Amood field is situated in Dhi Qar Governorate, $250 \mathrm{~km}$ south of Baghdad and is just $23 \mathrm{~km}$ southwest of Dujaila field. The area of Abu Amood field is approximately $120 \mathrm{~km}^{2}$ and it is situated in a northwest to southeast structural direction. The area's longitude is between 45.30 to 46.30 degrees and latitudes occur at 31 degrees. The field is thought to be an economically successful development sector (OEC, 2008). Tectonically, The Abu Amood Oil Field is situated within the Mesopotamian basin. In the Euphrates subzone of the stable shelf on basis of longitudinal tectonic classification of Iraq (Fig.1) (Jassim and Goff, 2006). The structure of the Abu Amood Oil field as shown in Fig.1 is an asymmetrical anticline and the axis extends toward Northwest-Southeast and the length is $22 \mathrm{~km}$ and width of 4-5 km with structural closure of about $60 \mathrm{~m}$ (OEC, 2008).

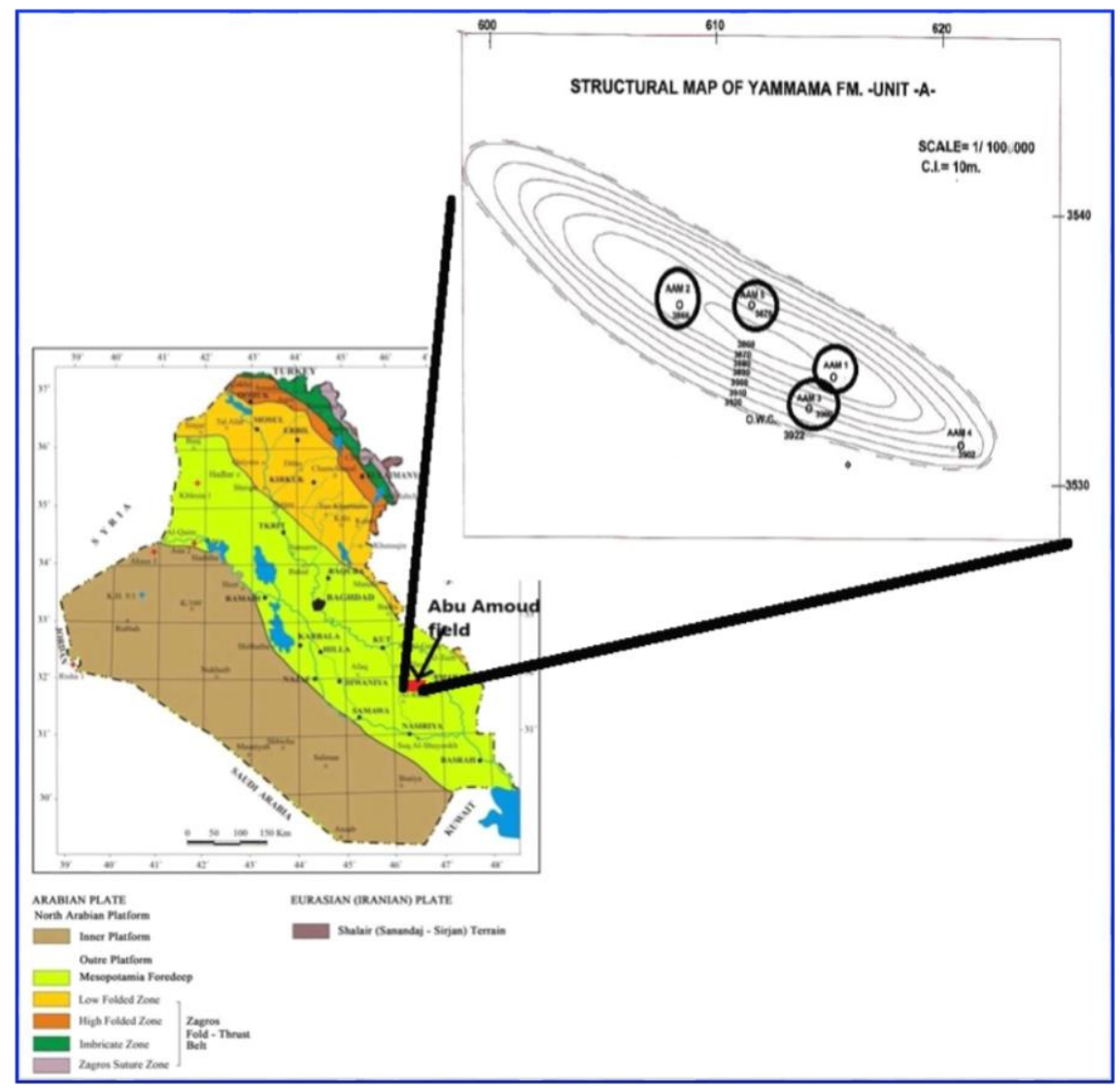

Fig.1. Location map of the study area (Jassim and Goff, 2006) and structural contour map of the Yamama Formation in Abu Amood Oil field (O.E.C.,2008)

\section{Geologic and Stratigraphic Setting}

The Yamama Formation is part of the late Berriasian-Aptian cycle, that aged to early Cretaceous, which is represented in the shore to deep basin by the Zubair, Ratawi, Garagu-Yamama, Shuaiba, Sarmord and lower Balambo formations. The formation generally grades conformably overlying the 
Sulaiy Formation and was underlain by Ratawi Formation. Where both the Yamama and Ratawi formations are missing that appears at Eastern Baghdad oil field, the Zubair Formation conformably overlies Jurassic rocks (Aqrawi et al., 2010). The formation consists of three periods of sedimentation in the south east of Iraq. The top of this cycle contains gravel sediments, as well as detailed peloidal facies that descends into a middle ramp bioclastic / coral / stromotoporoid pack - wackestone facies appear underneath the former. The Yamama basin in the south of Iraq such as Majnoon oil field and other fields is indicated as a ramp setting in a stable flank of the carbonate platform. The ramp setting effects on the stacking patterns of the Yamama Formation (Idan et al., 2020). The formation which is a heterogeneous carbonate supply, is one of the significant oil generation stores in southern Iraq, deposited during the Lower Cretaceous period inside the primary retrogressive depositional cycle (Barriasian Aptain ) south of Iraq .This cycle is reached out from shore to profound bowl by the Zubair ,Ratawi, Yamama ,Shuaiaba and Sulaiy formations (Budy,1980 and Aqrawi et al., 2010). The Yamama Formation is act to the one of the promising carbonate reservoirs, in light of its wide geographic dispersion over most part of southern Iraq, and comprise of one the richest petroleum systems lead to distinctive structure traps and presence of stable stratigraphic traps.

\section{Materials and Methods}

Wireline well logs are the main data used in characterizing the Yamama Formation in this study. The Didger software was used to digitize well logs. Digitizing is the process of transferring paper documents to computers. One reading per $0.25 \mathrm{~m}$ depth was selected for reading for selected wells (AAm-1, AAm-2, AAm-3, and AAm-5) as shown coordinates in the Table 1. This step was followed by carrying an environmental correction for the well logs. Techlog software was used to achieve the corrections and interpretation processes such as lithology and mineralogy identification, logs interpretation (porosity, water and hydrocarbon saturations determination) and petrophysical distribution maps using Kriging method. Kriging is an unbiased interpolation and extrapolation method which minimizes the variance estimate computed from the variogram of the property. The variogram measures the variance used to balance the influence of the distance between the wells. In this method, the Variance, the Nugget and the Range parameters to be used for the kriging are extracted from the modeled variogram (no default values). These three variables bound the modeled curve and are therefore a mandatory pre-step to the map computation itself.

Table 1. Studied wells coordinate in Abu Amood Oil Field.

\begin{tabular}{ccc}
\hline Well name & \multicolumn{2}{c}{ UTM coordinates } \\
\hline & Easting & Northering \\
AAm-1 & 614800 & 3533800 \\
AAm-2 & 608000 & 3536550 \\
AAm-3 & 613650 & 3532700 \\
AAm-4 & 611100 & 3536500 \\
\hline
\end{tabular}

\subsection{Petrophysical Parameters}

The petrophysical properties are calculated depending on standard equations which are deduced from Asquith and Krygowski (2004) as shown in Fig.2 that summarized the calculation steps.

\subsection{Lithological Analysis Using Cross plots}

Cross plots are diagrams based on the direction and cross-section of two logs response (dependent on pore fluid and matrix lithology). Due to its rock-fluid composition, this deposit may have a pore 
system of variable porosity (Hughes,1992). The neutron density cross-plot is an ancient research technique that is commonly used to evaluate the porosity and lithology of quartz, calcite, and dolomite. In this cross-plot, the sandstone (silica), limestone and dolostone are three lithology lines (dolomite). Lithology lines are typically marked by porosity values in percentages. Cross plot $\mathrm{M}-\mathrm{N}$ is used to categories the image, density and neutron mineral mixture to provide lithology-dependent quantities $\mathrm{M}$ and N. Cross plots of porosity combinations (density versus neutron cross plot, M-N and cross plot matrix identification) were used to classify the major Yamama Formation lithology and mineralogy.

$$
\begin{gathered}
\mathrm{M}=(\Delta \mathrm{tfl}-\Delta \mathrm{tlog}) /(\rho \mathrm{b}-\rho \mathrm{f}) \times 0.01 \\
\mathrm{~N}=(\emptyset \mathrm{Nf}-\varnothing \mathrm{N}) /(\rho \mathrm{b}-\rho \mathrm{f})
\end{gathered}
$$

Where:

$\Delta \mathrm{tf}=$ interval transit time for fresh water $=189 \mathrm{~m} / \mathrm{s}$ and $185 \mathrm{~m} / \mathrm{s}$ for salt mud.

$\Delta \mathrm{t}=$ soniclog reading. $\mathrm{Pb}=$ density log reading.

$\rho \mathrm{f}=$ density of fresh water $=1 \mathrm{~g} / \mathrm{cm} 3$ or $1.1 \mathrm{~g} / \mathrm{cm} 3$ for salt mud.

$\emptyset \mathrm{Nf}=$ Porosity of Neutrons for Fluid $=1 . \quad \varnothing \mathrm{N}=$ neutron porosity.

In Fig.3, mostly plotted data fall to limestone line which indicated dominant limestone lithology for the Yamama Formation and some of the samples close to sandstone but remain as limestone especially at well AAm-1 with few data represent some meters of dolomite fall to dolomite line as wells AAm-1 and AAm-5. In Fig.4 of M-N mineralogy plot in all studied wells show plotted data located in calcite area with extension toward secondary porosity especially at wells AAm-1 and AAm-5.

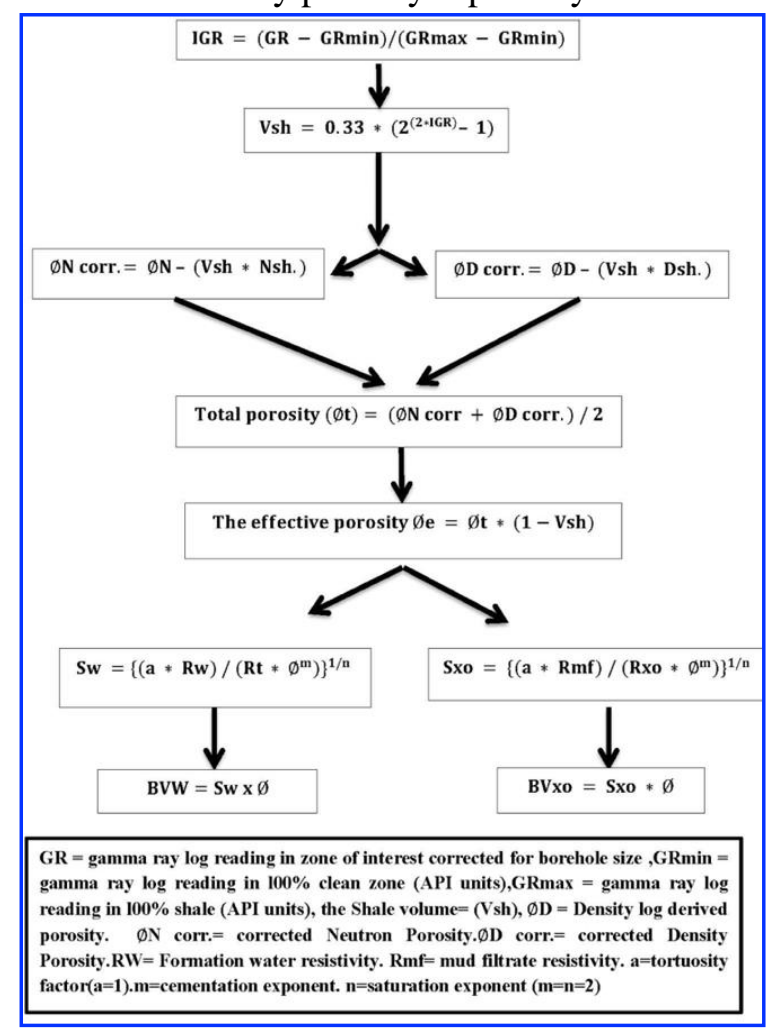

Fig. 2. Diagram illustrates steps and parameters of petrophysical properties 


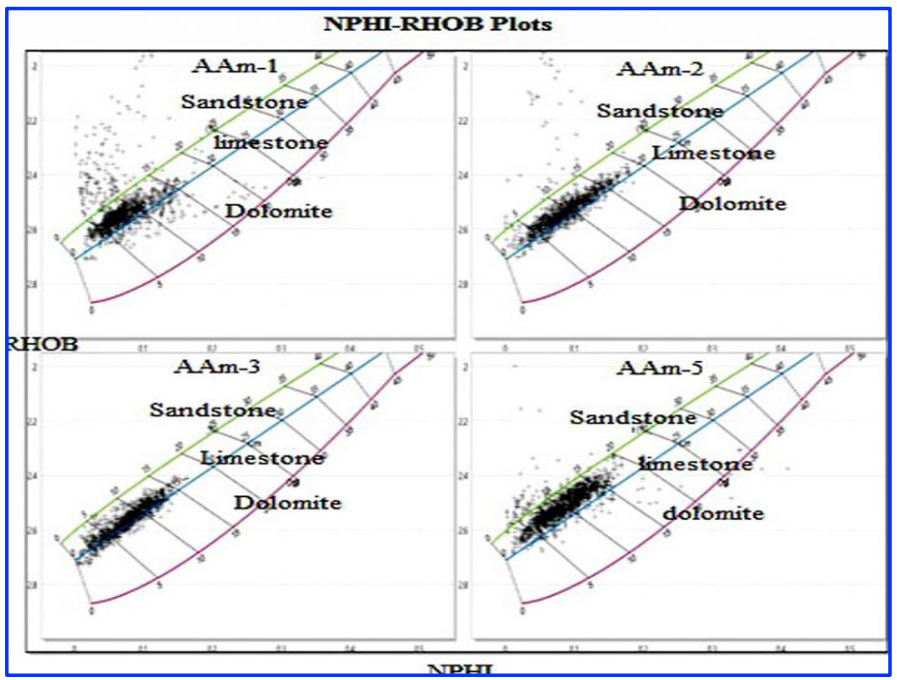

Fig. 3. Neutron-density cross plots for studied wells

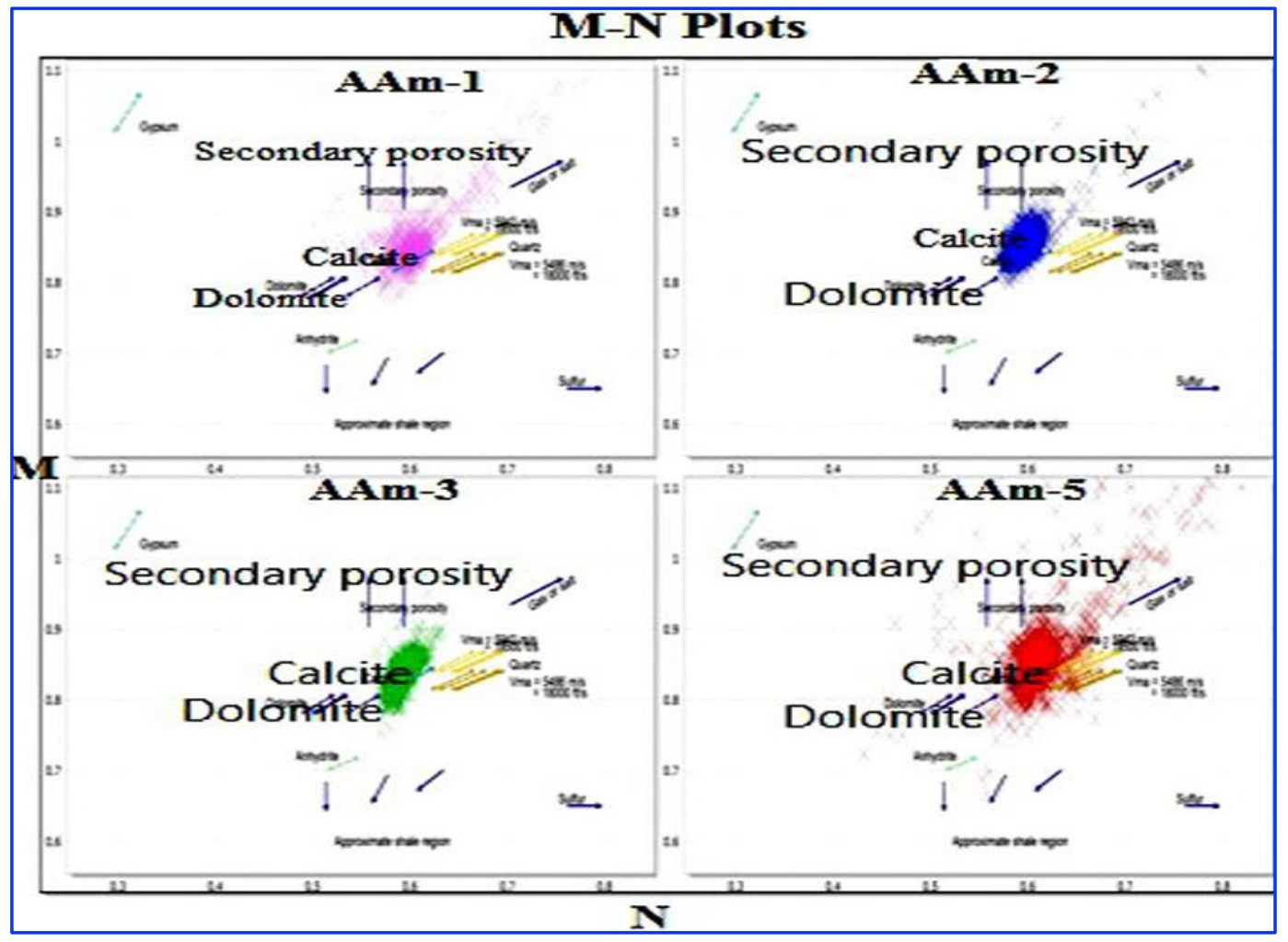

Fig.4. M-N mineralogical cross plots for studied wells

\section{Results and Discussions}

The procedures of interpretation include assessment of petrophysical properties from well log information provided in computer processed interpretations (CPI) as shown in Figs. 5, 6, 7, and 8. These figures show that the Yamama Formation at Abu Amood Oil field, which is composed of limestone or argillaceous thin bed, multiple oil column reservoir, is composed of six reservoir units extend through wells (AAm-1, AAm-2 and AAm-5) and Five reservoir units extend through well AAm-3. These units are YB-1, YB-2, YB-3, YC-1, YC-2 and Yc-3, which vary in their petrophysical properties and separated by low-porosity barrier beds. Correlation section between studied wells. fig. 9 shows a vertical distribution of effective porosity at the Yamama units that appears as good porosity at wells AAm-1, 
AAm-2 and AAm-5 whereas decreases at well AAm-3. The uppermost unit within the Yamama Formation in the Abu Amood Oil Field is YB-1. The thickness of this unit varies anywhere from 26 to 28 meters with moderate to good petrophysical properties, total porosity distribution from 3 to $26 \%$, and a water saturation range from 9 to $87 \%$ in the wells. The Unit YB-2 is characterized by good reservoir properties including porosity with range between 0.02-0.21 and water saturation range between 0.140.72 is interpreted as an oil-bearing region. The YB-3 unit is much thinner and has a porosity range between $0.02-0.13$ which is perceived as a water-bearing region. The porosity of YC-1unit shows a low value range between $0.011-0.12$ with a water saturation $0.22-0.82$. This unit is bad unit. The YC-2 unit has a high thickness and is distinguished by very strong reservoir properties. The porosity distributes between $0.03-0.20$ and water saturation range between $0.24-0.85$. This particular unit was considered as an oil-bearing zone. The Yamama unit YC-3 represents the lowermost unit within the Yamama Formation in the AAm-1, AAm-2 and AAm- 5 wells. Porosity distribution between 0.04 and 0.26 , and water saturation of between 0.27 and 0.77 , is interpreted as a sedimentary unit oil-bearing. In order to distribute petrophysical properties horizontally such as porosity and water saturation, 2D Kriging maps have been developed to define spatial relationships between porosity and water saturation using average values for each unit in each well. The horizontal variation of the petrophysical properties of the principle oil bearing YB-2 and YC-2 units are shown in figs. 10 and 11 as porosity contour maps. The porosity is relatively high near the upper western areas around wells AAm-2 and AAm-5 but decreases toward well AAm-1.The areal variation of the water saturation of units YB-2 and YC-2 may be noticed in figs. 12 and 13. A diverse range of water saturation is observed around the well AAm-5. At the well AAm-5, water saturation improves in all directions away from this well. This is particularly the case towards the south-east direction.

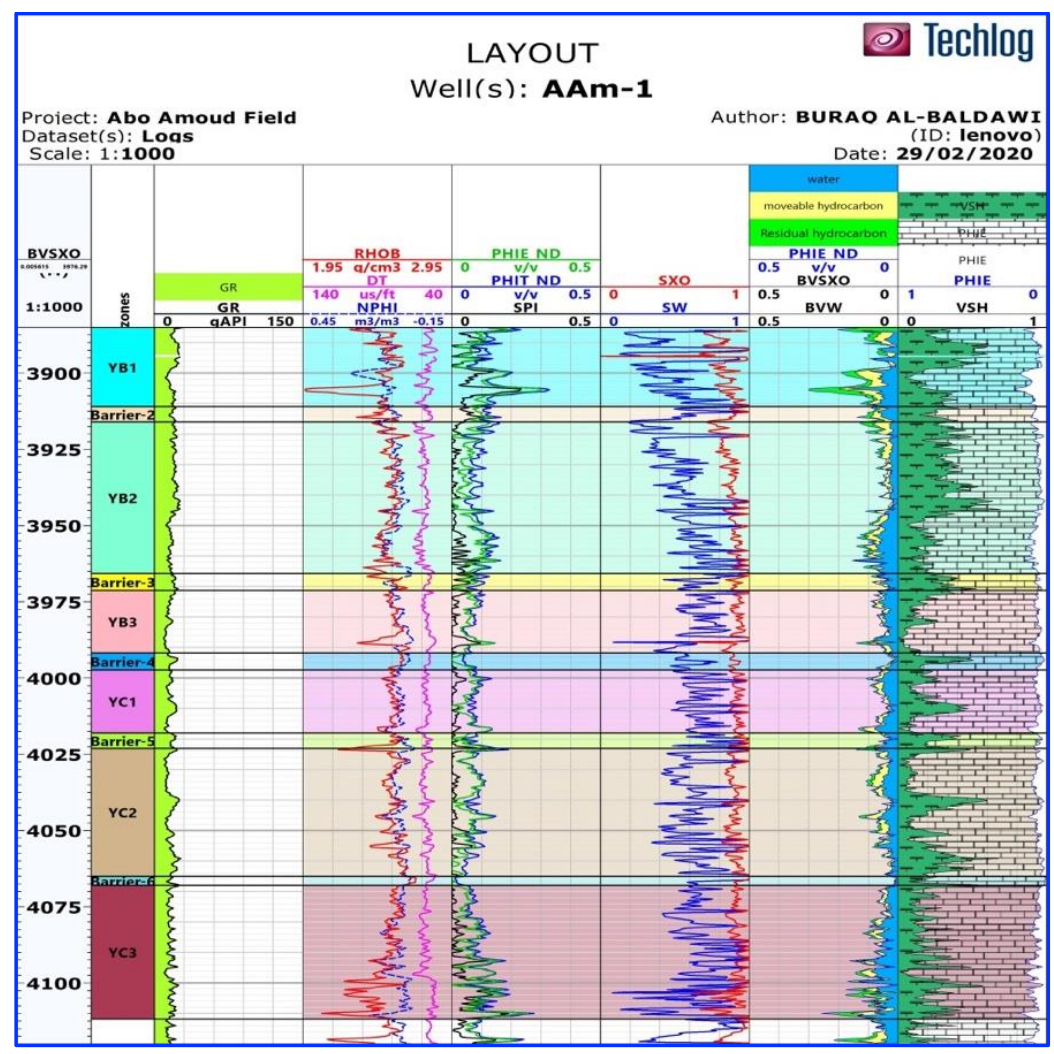

Fig. 5. CPI for well AAm-1 


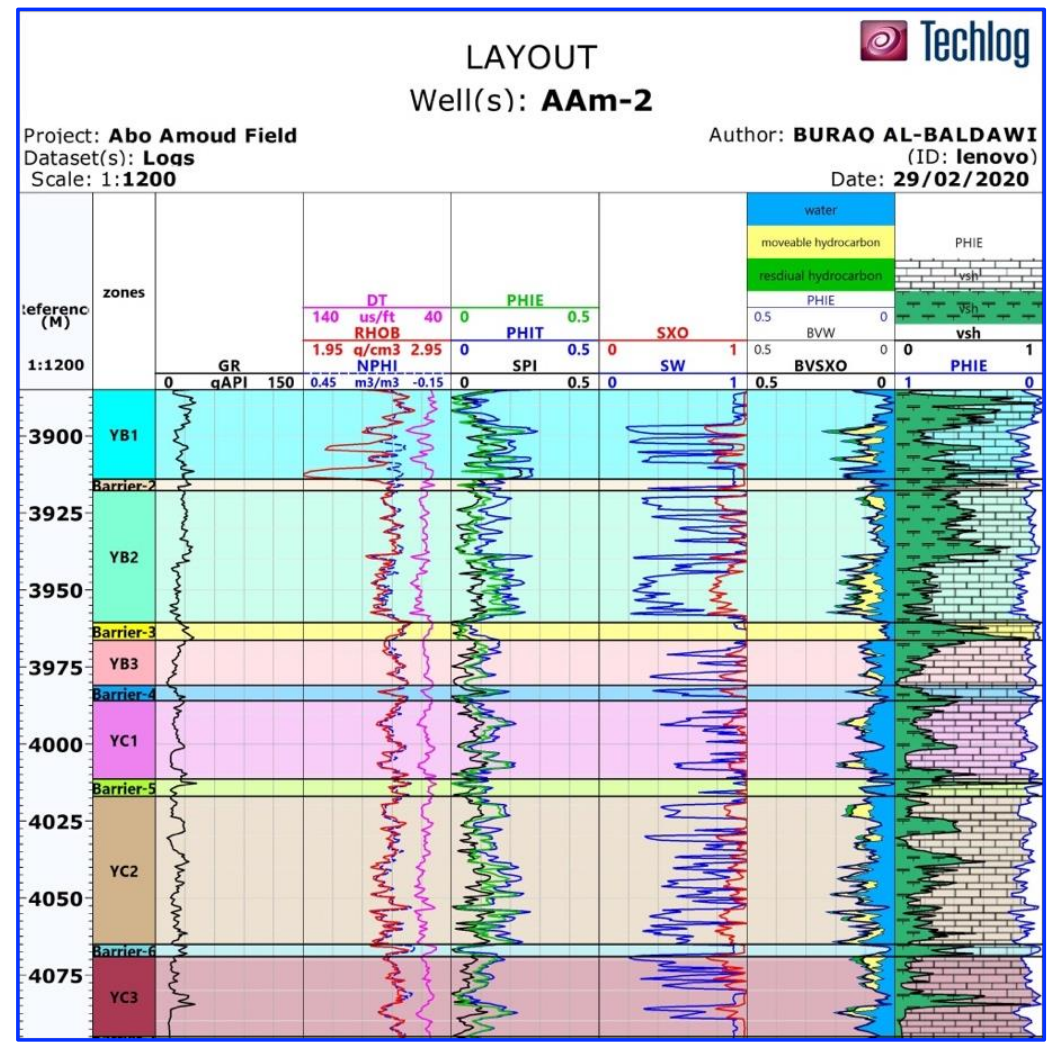

Fig. 6. CPI for well AAm-2

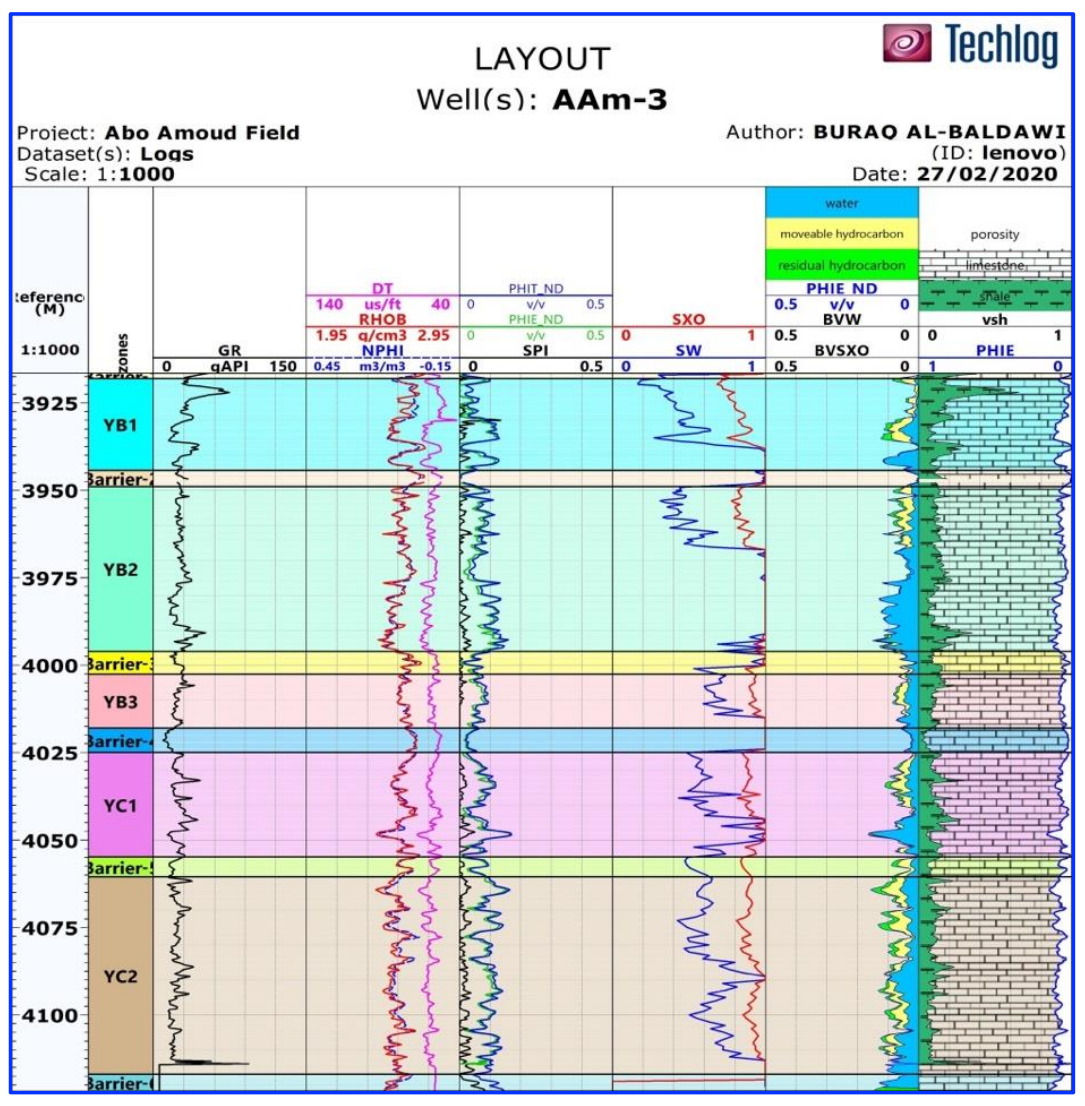

Fig.7. CPI for well AAm-3 


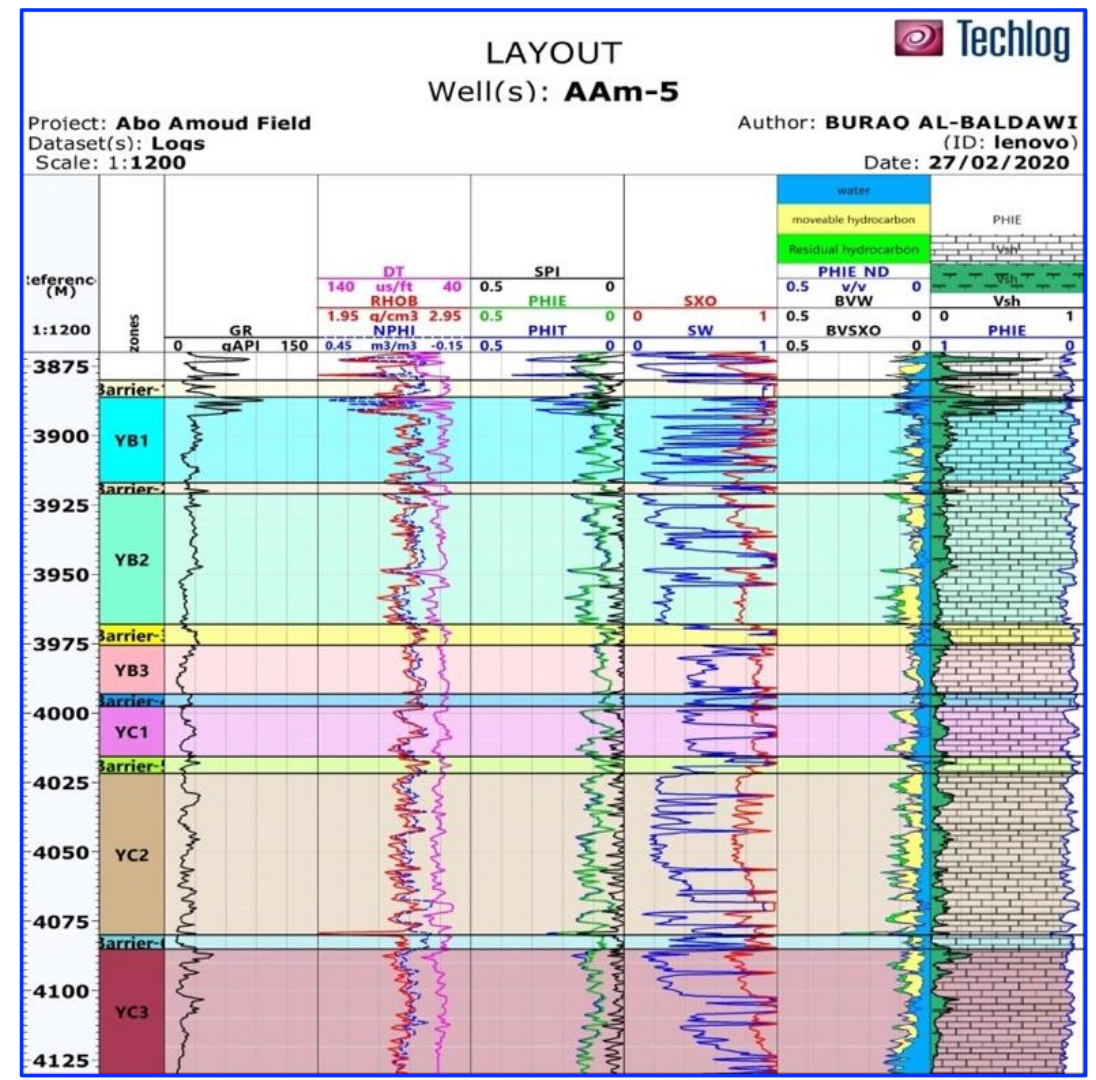

Fig. 8. CPI for well AAm-5

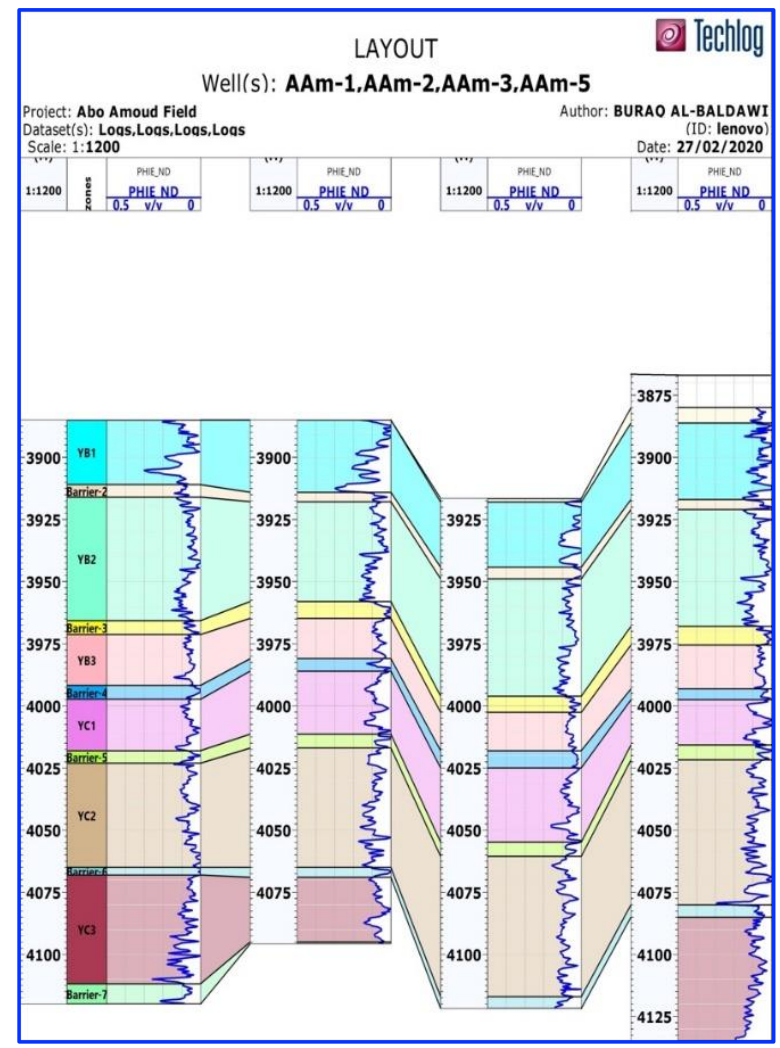

Fig.9. Correlation section along studied wells showing vertical distribution of effective porosity in Yamama units 


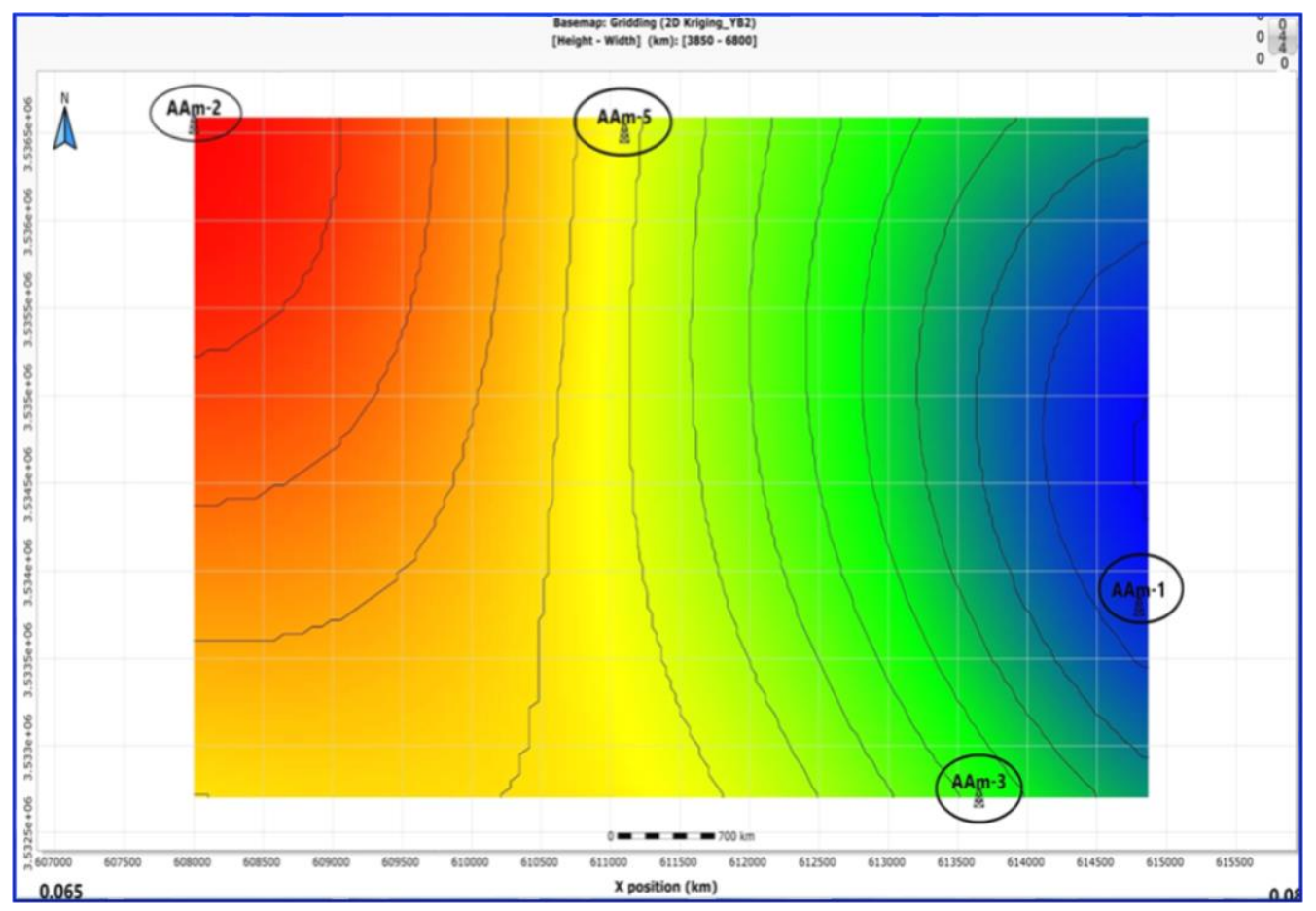

Fig.10. 2D Kriging porosity map for unit YB-2

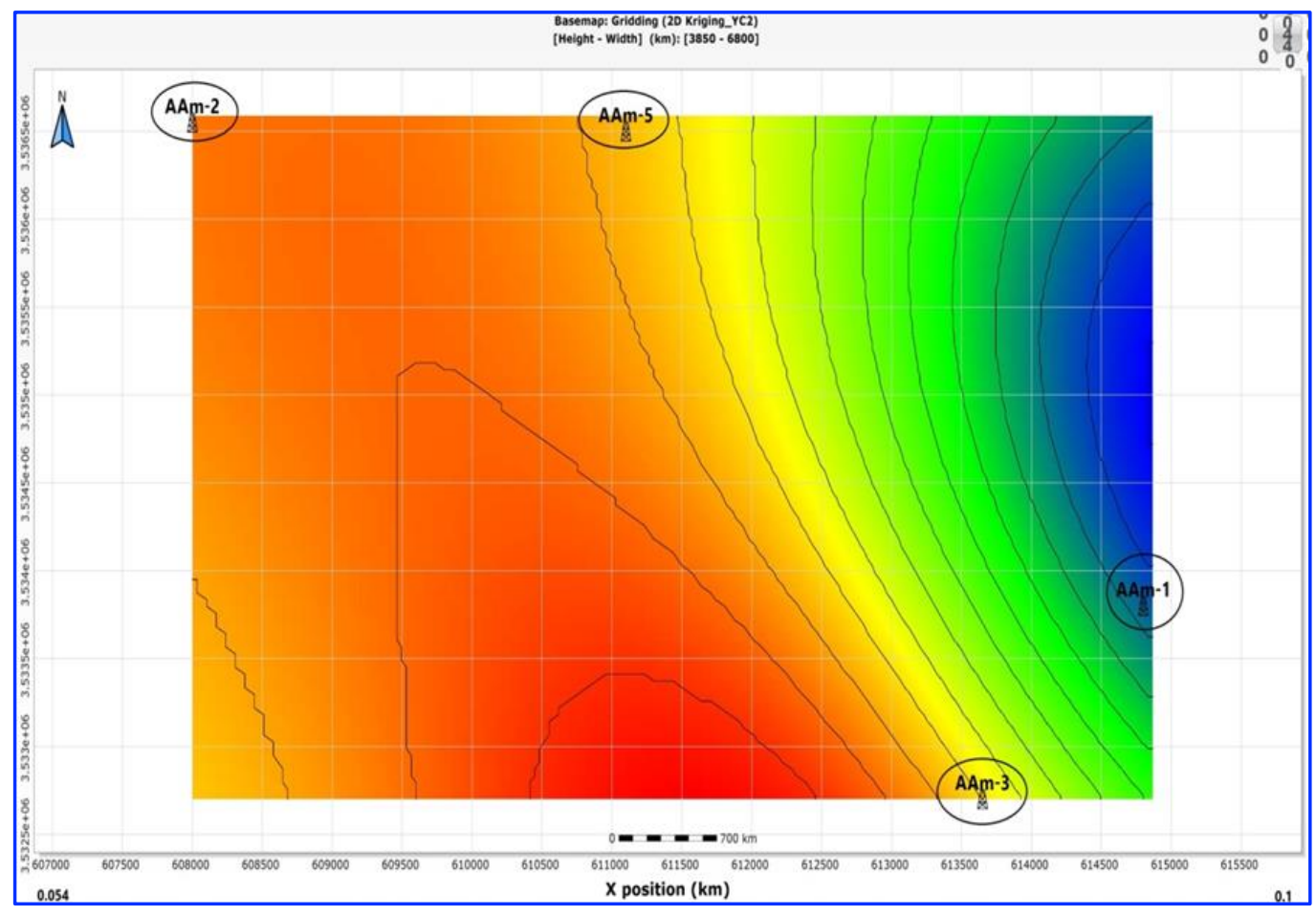

Fig.11. 2D Kriging porosity map for unit YC-2 


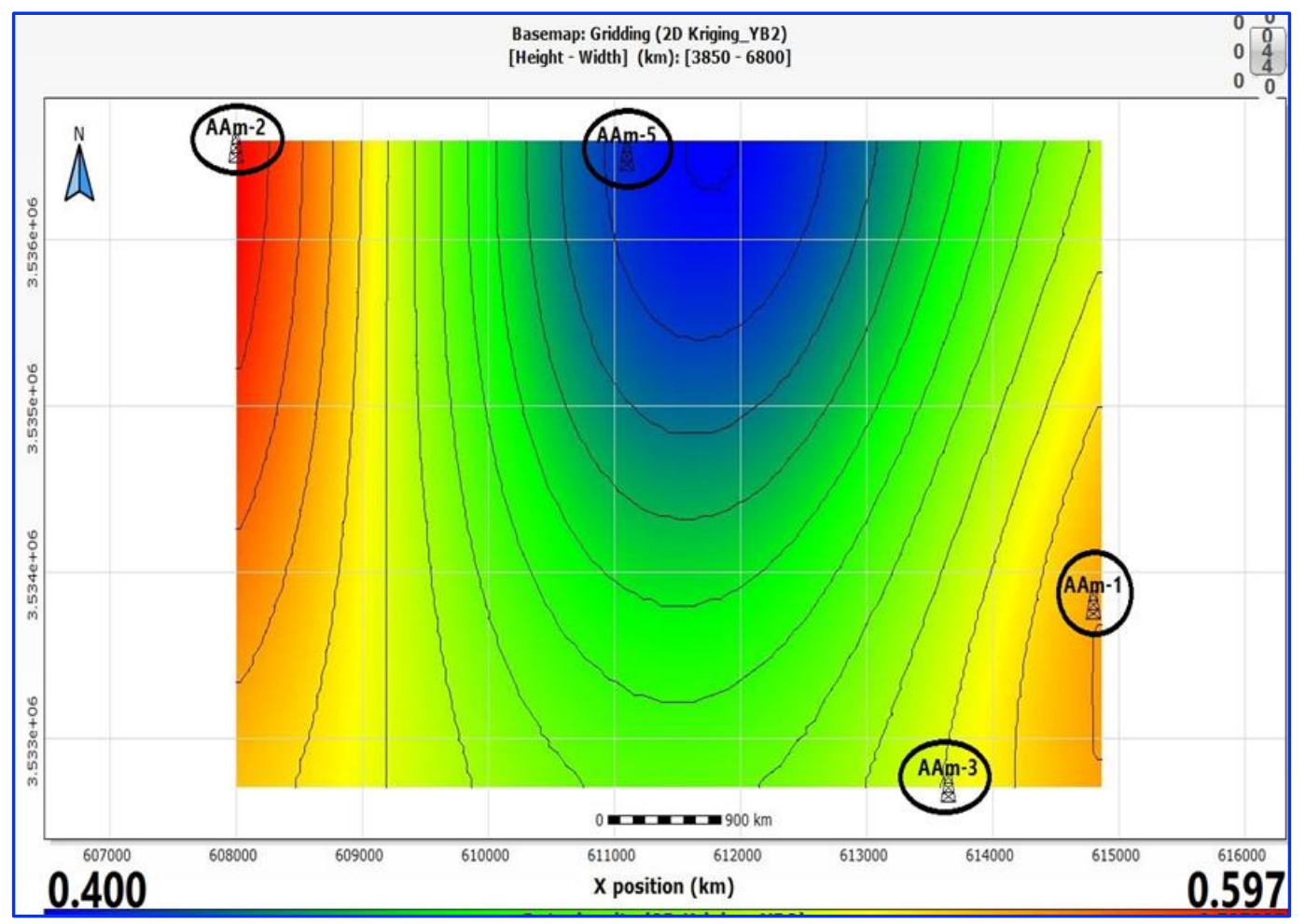

Fig.12. 2D Kriging water saturation map for unit YB-2

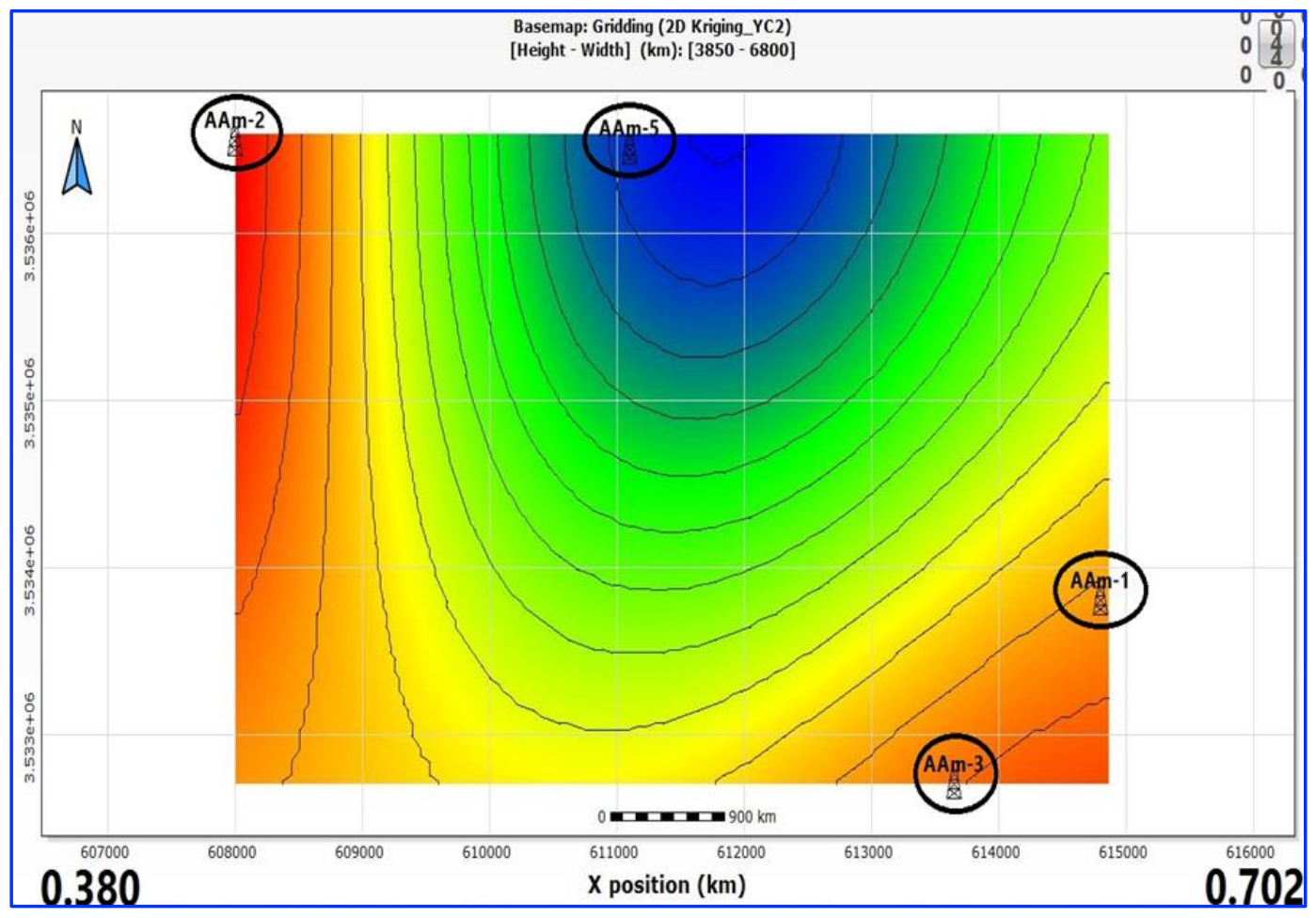

Fig.13. 2D Kriging water saturation map for unit YC-2 


\section{Conclusions}

The lithological and mineralogical studies of the Yamama Formation indicate that the formation is mostly limestone with calcite as a main mineral in the formation. The Yamama Formation has low porosity values relative to other Cretaceous reservoirs of the Middle East. Total and effective porosities in the rock are measured using neutron, density and sonic logs which reveal that the rock's primary porosity is larger than the secondary porosity. The Yamama Formation at Abu Amood Field is subdivided into six reservoir units extend through wells (AAm-1, AAm-2 and AAm-5). Depending on well logs and CPI separated by low Porosity and high-water saturation barrier beds. These units are YB1, YB-2, YB-3, YC-1, YC-2 and YC-3. The CPI figures illustrate that the thickness increasing from the NW at AAm-5 to SE direction at AAm-1, also the petrophysical properties enhance in the same directions in AAm-5 and AAm-1 respectively and decreasing in AAm-2 and AAm-3. The computer 2D kriging maps and computer processed interpretation are showed that reservoir units YB-1, YB-2, YC-2 and $\mathrm{YC}-3$ have strong reservoir properties and oil-bearing areas. The water saturation within reservoir units, YB-1, YB-2 and YC-3 characterized by almost low, and moderately within reservoir units, YB3, YC-1 and YC-2.

\section{Acknowledgements}

The authors would like to thank the Department of Geology, University of Salahaddin. The author is very grateful to the Editor in Chief Prof. Dr. Salih M. Awadh, the Secretary of Journal Mr. Samir R. Hijab and the Technical Editors for their great efforts and valuable comments.

\section{References}

Aqrawi, A., Horbury, A. D., Goff, J., Sadooni, F., 2010. The Petroleum Geology of Iraq. State oil, 424 pp.

Asquith, G. B., Krygowski, D., 2004, Basic Well Log Analysis, 2nd Edition: AAPG Methods in Exploration Series 16. Published by The American Association of Petroleum Geologists Tulsa, Oklahoma, 244 pp.

Buday, T., 1980. The Regional Geology of Iraq, Stratigraphy and Paleogeography, State Organization for minerals, Baghdad, 242-245 pp.

Hughes, B. 1992. Advanced Wierline and MWD Procedure Manual. Huston.

Idan, R. M., Salih, A. L. M., Al-Khazraji, O. N. A., Khudhair, M. H., 2020. Depositional environments, facies distribution, and porosity analysis of Yamama Formation in majnoon oilfield. Sequence stratigraphic approach. Iraqi Geological Journal, 53(1D), 38-52.

Jassim, S. Z., Goff, J. C., 2006. Geology of Iraq. Dolin, Prague and Moravian Museum, Brno, 341 pp.

Oil Exploration Company (OEC), 2008. Geological evaluation study for Abu Amood field. Geology Department., Ministry of Oil, Baghdad, Iraq. 